\title{
Approach and treatment of suicidal behavior in the clinical practice of different groups of health professionals in Spain: results of the project EUREGENAS
}

\author{
MODELOS DE INTERVENCIÓN EN LA CONDUCTA SUICIDA SEGÚN DIFERENTES \\ PROFESIONALES SANITARIOS EN ESPAÑA: RESULTADOS DEL PROYECTO EUREGENAS \\ MODELOS DE INTERVENÇÃO COMPORTAMENTO SUICIDA PELOS PROFISSIONAIS \\ DE SAÚDE DIFERENTES EM ESPANHA: PROJETO RESULTA EUREGENAS.
}

\author{
Juan Luis Muñoz¹, María Cruz Sánchez Gómez², Beatriz Palacios Vicario³, Manuel Ángel \\ Franco Martín ${ }^{4}$
}

\begin{abstract}
According to the WHO and the European Union, suicide is considered to be a health problem of prime importance and to be one of the principal causes of unnatural death. In Spain, the number of suicides has increased 12\% since 2005 (INE). The Research Project "European Regions Enforcing Actions against Suicide (EUREGENAS), funded by the Health Program 2008-2013, has as main objective the description of an integrated model of Mental Health orientated to the prevention of suicide. The differences that allow distinguishing the meaning of prevention in suicide behavior are described and explained through a qualitative methodological strategy and through the creation of discussion groups formed by different groups of health professionals. The results highlight the existing differences between the diverse health professionals who come more in contact with this problem and it shows as well the coincidence of meaning that suicide has to be considered as a priority in the field of health.
\end{abstract}

\section{DESCRIPTORS \\ Suicide \\ Prevention \\ Health professionals \\ Cualitative \\ EUREGENAS}

\section{RESUMEN}

Según la OMS y la Unión Europea, consideran el suicidio un problema de primer orden y una de las principales causas de muerte no natural. En España, la tasa ha aumentado un 12\% desde 2005 (1). El Proyecto de Investigación Euroepan Regions Enforcing Actions against Suicide (EUREGENAS) financiado por Health Progam 20082013, tiene como principal objetivo describir un modelo integrado de Salud Mental orientado a la prevención de suicidio. A través de una estrategia metodológica cualitativa y mediante la elaboración de grupos de discusión con distintos colectivos profesionales de la salud se describen e interpretan las diferencias que permiten discriminar el significado de la prevención de conductas suicidas. Los resultados ponen en evidencia las diferencias existentes entre los diferentes profesionales de la salud más relacionados con este problema y la coincidencia en considerar el suicidio como una prioridad en el ámbito de la salud.

\author{
DESCRIPTORES \\ Suicidio \\ Prevención \\ Profesionales de la salud \\ Cualitativo \\ EUREGENAS
}

\begin{abstract}
RESUMO
De acordo com a OMS e a União Europeia o suicídio é considerado um problema de primeira ordem e uma das principais causas de morte não natural. Em Espanha, a taxa aumentou 12\% desde 2005 (INE, 20014). O projeto de investigação Regiões Europeias Promovendo Acções contra o Suicídio (EUREGENAS), financiado pelo Programa de Saúde 2007-2013, tem como objetivo principal promover um modelo integrado de saúde mental para prevenir o suicídio. Através de uma estratégia metodológica qualitativa e do desenvolvimento de grupos de discusão com diferentes profissionais de saúde, são descritas e interpretadas as diferenças que permitem identificar como discriminar o significado da prevenção de comportamentos suicidas. Os resultados evidenciam as diferenças entre os pontos de vista e práticas dos diferentes profissionais da saúde relacionados com este problema, e a ideia reconhecida em considerar o suicídio como uma prioridade no campo da saúde.
\end{abstract}

\author{
DESCRITORES \\ Suicídio \\ Prevenção \\ Profissionais de saúde \\ Qualitativo \\ EUREGENAS
}

\footnotetext{
${ }^{1}$ Medical Doctor. Psychiatrist. Head of Psychogeriatric Unity at Psychiatry Department of Zamora Virgen de la Concha Hospital. PhD student in Suicidality. Researcher of European research projects and clinical trials, Spain. ${ }^{2}$ Doctor and graduate in educational sciences from the University of Salamanca and has a Masters in speech therapy from the Pontificia University of Salamanca (Spain). Department of Didactics and Research Methods. Faculty of Education. University of Salamanca, Spain. ${ }^{3}$ Doctor of Psychology in the Psychology Faculty at the Pontifical University of Salamanca. Professor of subjects related to research methodology in Psychology and Sciences of Physical Activity and Sport. Professor in various Masters in subjects research methodology, España. ${ }^{4}$ Psychiatrist. Head of psychiatric Deparment at Zamora Hospital. Associate Professor of Salamanca University; Head of RDI Area at INTRAS Foundation. Member of the Salamanca Medicine Academy. Superviser ESRs PhD projects registered at Salamanca University. Leader of European research projects and clinical trials, Spain.
} 


\section{INTRODUCTION}

Suicide is a serious public health problem which is one of the most frequent causes of unnatural death in the world ${ }^{(2)}$. It is estimated that in the last 45 years the prevalence of suicide has increased by $60 \%$, what turns it into the tenth leading cause of death worldwide and into one of the three main causes of death in persons between 15 and 44 years old ${ }^{(3)}$.

Europe has a high suicide rate overall, but the epidemiology of suicide differs considerably from country to ${ }^{(4)}$. Some countries such as Finland, Hungary and the Baltic countries, together with Russia and Belarus, have the highest suicide rates in the world reaching 40 suicides per 100.000 inhabitants. Nevertheless, southern European countries such as Italy, Spain and Greece show low suicide rates ${ }^{(5)}$. Although Spain is positioned among the European countries with lower suicide rates, during the last years this cause of death has increased substantially in our country. According to the data of the National Institute of Statistics ${ }^{(1)}$, the number of suicides increased in Spain by $11,3 \%$ in 2012 , what is the highest rate since $2005^{(1)}$.

Suicidal behavior is a complex phenomenon that is influenced by multiple factors, including biological, clinical, psychological and social factors ${ }^{(6)}$. Suicide is closely linked to the model of society in which an individual lives ${ }^{(7)}$, and there exists a direct relationship between the suffering of stressful situations, environment alterations and the risk of suicide ${ }^{(8)}$. It has been proved that living in an environment with favorable life conditions and living without economic hardship decreases the risk of suicide ${ }^{(9-11)}$. Regarding the marital status, divorced people run the highest risk of suicide ${ }^{(12,13)}$. Being a person with religious beliefs is usually a protective factor proportional to the degree of religiosity of the individual ${ }^{(14,15)}$.

Suicidal acts are usually preceded by milder symptoms such as thoughts of death or suicidal ideation ${ }^{(16)}$. This progression of thought towards the act represents, in the suicide process, a transition from mild symptoms to more severe ones ${ }^{(17)}$. This prodromal symptomatology is a risk factor for future hospital admissions because of suicide attempts or it is a risk factor for death by suicide ${ }^{(18)}$. A large number of studies, clinical as well as community ones, have shown with consistent scientific evidence that the presence or a background of mental illness is a major risk factor for suicide in the population in general|(19-21). Mood disorders and disorders of the control of impulses due to the consumption of alcohol and substances are the psychotic and personality disorders that carry the highest risk of suicide and of suicidal behaviors ${ }^{(22-24)}$.

In an attempt to reach a breakthrough in the field of suicide prevention in Europe, the Project European Regions Enforcing Actions against Suicide (EUREGENAS) brings together 11 regions which have diverse experiences in order to contribute to the prevention of suicide in Europe.

\section{METHOD}

The European Regions Enforcing Actions against Suicide Project (EUREGENAS), is funded by Health Program 2008-2013, European Union. Castilla y León is one of the two Spanish regions that participate in the Project and it is represented by the Foundation INTRAS. The overall aims of the project are the implementation of awareness activities with local and community consultants, in order to create a network of suicide risk detection; to offer training for doctors who work at primary care, and to give support to survivors of suicide (family and near friends of the person who committed suicide).

The methodology used for this study is a qualitative analysis carried out by the research group of the University of Salamanca and the Pontifical University of Salamanca. They used discourses of several health professionals, which comprise psychologists, psychiatrists, primary care staff (general practitioners) and staff of the emergency services. The aim was to describe and to explain the differences that allow distinguishing the meaning of the prevention of suicidal behavior among these professional collectives.

To complete the discursive space regarding the development of prevention, the discussion group method was used. Through discussion groups we obtain information about a specific topic of a social context, where people can express their views in interaction with others. As criteria for the distribution of the groups we used the health staff variable, which consists of four categories: psychologists, psychiatrists, staff of the emergency service and primary care staff. The recruitment of participants took place in the health area of Zamora and in the different centers of the INTRAS foundation. We structured the groups on a balanced way as far as the stratum, following the selection variable. The length of the sessions ranged from 1 hour to 1,5 hours, and they were recorded on digital video and audio, with written consent from the participants. Five groups were interviewed, with a number of people ranging from seven and ten, which in the opinion of the research team, and in light of the results of the data analysis, saturated the discursive space. The meetings took place smoothly and in a participatory environment that encouraged the participants to speak freely, expressing their ideas individually and interactively. In order to ensure, as far as possible, conditions that provided similar discourses in all the groups, the research team decided not to bring up expressions directly related to the topic. This way we could detect how and on which way these notions arose in the spontaneous progression of the sessions. To achieve this goal, the dynamics of the groups took place in an open and non-directive manner. Only when the session was about to end, and the groups had already developed their discourses, if on a spontaneous way all the desired goals were not achieved, the moderators suggested
Approach and treatment of suicidal behavior in the clinical practice of different groups of health professionals in Spain: results of the project EUREGENAS Muñoz JL, Gómez MCS, Vicario BP, Martín MAF 
more directly, to the groups to express their views on other issues related to the subject in question. The application of the qualitative analysis program NVIVO 10 was used for the transcript of the discussion groups. The data analysis consists of two phases that arise from different analytical approaches: a first phase is used to detect the discursive positions and the symbolic configurations of the texts ${ }^{(25)}$, and in the second phase, we follow the analytical model of Miles and Huberman(26).
In addition, we use a computer application, namely the qualitative data analysis program NVIVO 10, to facilitate the task of analysis.

\section{RESULTS}

The research results are obtained by taking into account the system of categories "Intervention in risk behavior". Category 1 is Labor Relevance given to suicide prevention.

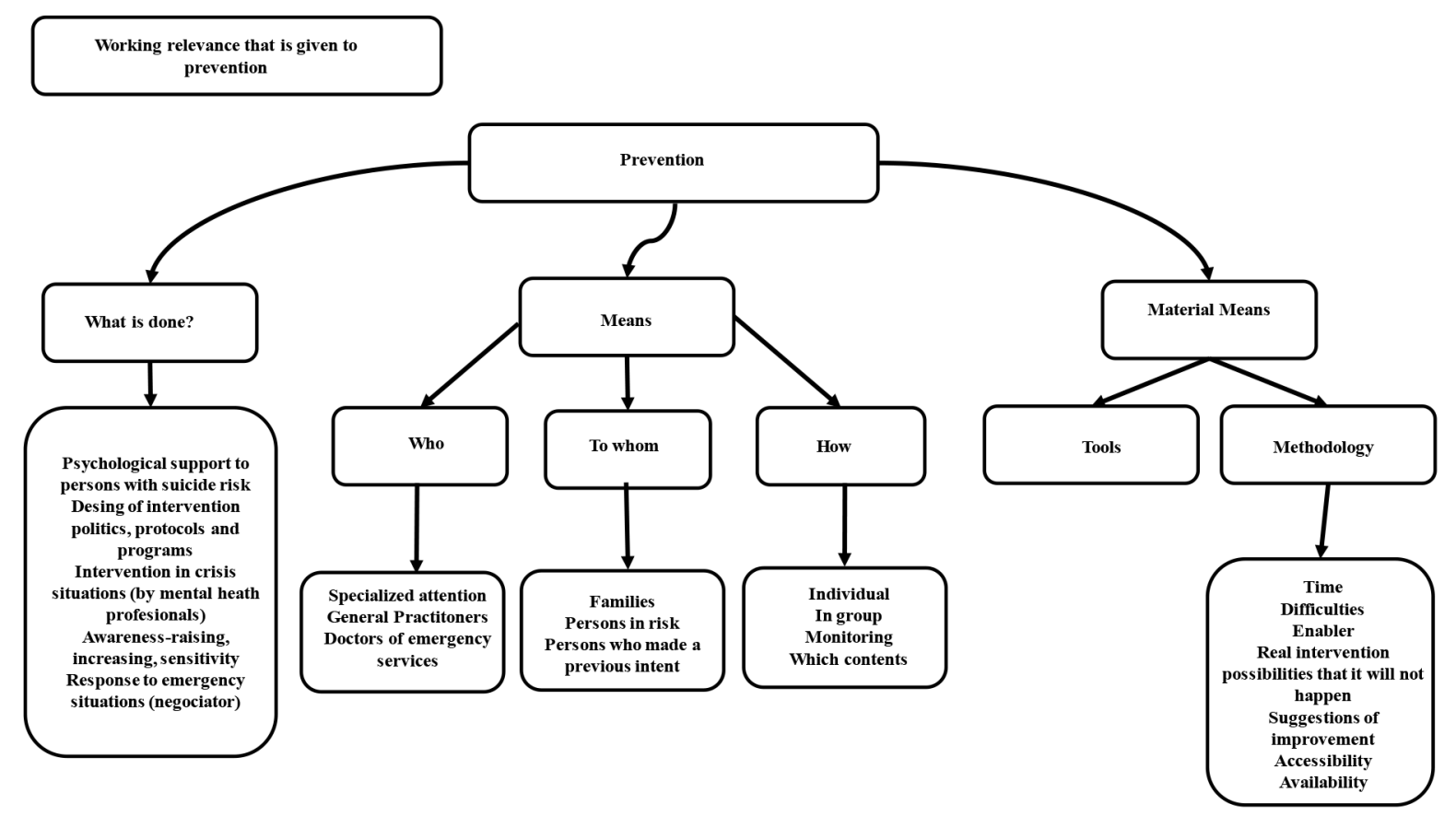

Figure 1 - System of categories "interenvention in risk behavior" (owner elaboration)

The importance that the different discussion groups, and therefore, the different health professionals, give to prevention differs. We detect that it is an important issue for professionals of the emergency service and of the primary care service and for psychologists. This might be due to the fact that these professionals are usually the first ones to receive this kind of patients.

-"Yes, because they are the ones who need more attention, they need more care" (doctor of the emergency service).

Category 2 is Prevention, what is being done? The staff of the primary care service is the group of professionals that asks to a greater extent for activities related to the training in suicide prevention. They argue not to be prepared to take care of patients with suicidal behavior, and even less in actions related to intervention in emergency situations for which they consider themselves not to be prepared and they act according to the seriousness they think the case in question might have. The discussion groups of psychologists instead emphasize on actions as the development of policies, protocols, and intervention programs. In this sense, psychiatrists seem to have the same view as psychologists, although psychiatrists prioritize the training in prevention instead of the development of policies, protocols, and intervention programs. The professionals of the emergency service emphasize on the immediacy of their performance as staff of the emergency service, informing the psychiatrist as soon as there is a minor indication of suicidal intentions on behalf of the patient In addition, all the professionals who participated in the discussion groups highlight, although in a lesser extent, other actions such as "psychological support for people at risk of suicide" and "awareness and sensitivity".

-"I think we are not prepared, I am only speaking in general
eh" (a general practitioner).

-"We have to be sure about the fact that we do not have structured and specific prevention programs" (a psychologist).

-"We always, always call the psychiatrist" (a doctor of the emergency service). 
-"I am telling you that we have to be sensitive with this issue and we should try to detect it in other kind of patients who we receive for other reasons" (a doctor of the emergency service).

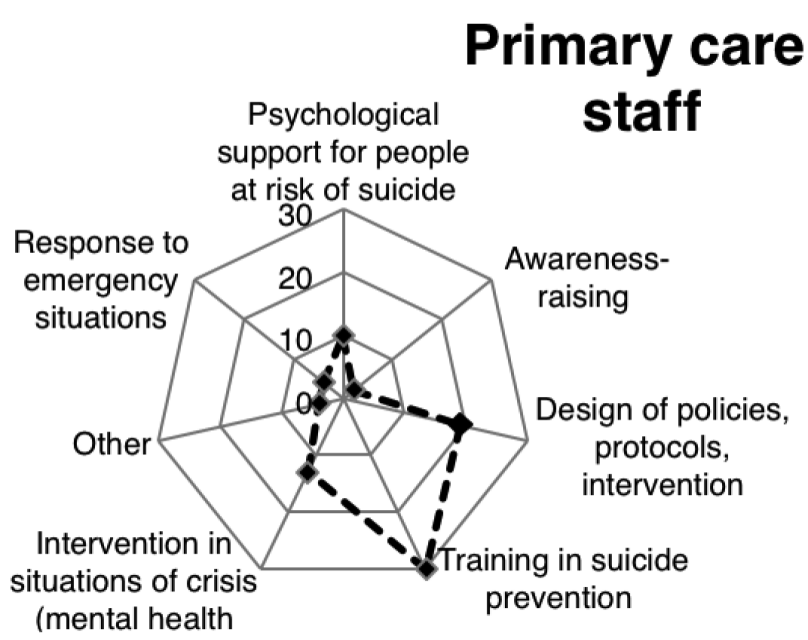

Graphic 1 - Importance of prevention (what is?) For primary health care (owner elaboration)

Category 3 is Prevention, what should be done? Human and material resources. The groups emphasized on the following aspects: accessibility, difficulties, availability, abilities, real possibilities of action which are not done, the time, and they also presented some suggestions for improvement. The different discussion groups, especially the primary care staff, psychiatrists and staff of the emergency service, are above all worried about the difficulties. Some comments of the participants were: "Maybe there are not enough professionals" (primary care staff)

\footnotetext{
-"The case, as difficulty I mean at social level, is the huge difficulty the professional is confronted with when he takes decisions that are very technical, very clear and very correct. Afterwards we have the social context by the media ... that converts everything, whatever it is. Why? Because it is very easy that everybody, but everybody deduces and not always discerning and not with, what we call clear clinical rigor" (Psychiatrist)
}

-"The truth is that prevention from an emergency service is very difficult. Or better said, it is impossible. Preventive attitudes are impossible" (Staff of the Emergency Service)

-"Achieving a total prevention is impossible" (Staff of the Emergency Service)

\section{DISCUSSION}

The participants in this study are people who belong to different groups of health professionals who share a close relationship with suicidal behavior during their regular clinical practice. This gives them a prominent role when it comes to analyzing the needs for improvement in this field.

All the participating professionals agree that suicide is a priority in the field of health, especially in relation to the necessities of intervention for the prevention of this serious public health problem. All the professionals express in a meaningful way how difficult it is for them to identify people who are at risk of suicide. In this sense, Pagura refers to the existence of a large number of people who, in spite of finding themselves in a high risk suicide situation, do not realize the magnitude of this problem. Thus, they never get to ask for any kind of help, neither from relatives nor from health professionals, what limits considerably the intervention of health professionals ${ }^{(27)}$. In this same concept, there are many people who, after having had a suicide attempt, do not maintain a correct continuation of the psychiatric treatment or they stop with the medical supervision ${ }^{(28)}$. On the other hand, most of the professionals highlight the need of improving the attention towards persons with suicide risk and they emphasize on the need to establish a prolonged care for people who have committed a failed suicide attempt. Finally, the whole of professionals stresses on the need to establish clear protocols of intervention or procedures as specific programs of suicide prevention.

For professionals working at the emergency services, the existence of a psychiatrist who deals with emergencies in these services of a general hospital is a key aspect in the urgent attention of suicidal behavior, and it is very well appreciated by the patients themselves as well as by the staff. These professionals agree in considering this kind of patients as an emergency to which they give high priority, which can be compared for instance with an acute heart attack. Nevertheless, they point out that when decisions have to be made, they always ask for the assistance of a psychiatrist. This way they show that their field of intervention is more centered in an attention that focuses on the stabilizing of the patient on a somatic level. In relation to this, it should be pointed out that not all the patients with this kind of behavior have the same degree of emergency of intervention. Each case is based on socio-demographic factors such as age or gender, as well as on the method of self-injury the patient used ${ }^{(29)}$.
Approach and treatment of suicidal behavior in the clinical practice of different groups of health professionals in Spain: results of the project EUREGENAS Muñoz JL, Gómez MCS, Vicario BP, Martín MAF 


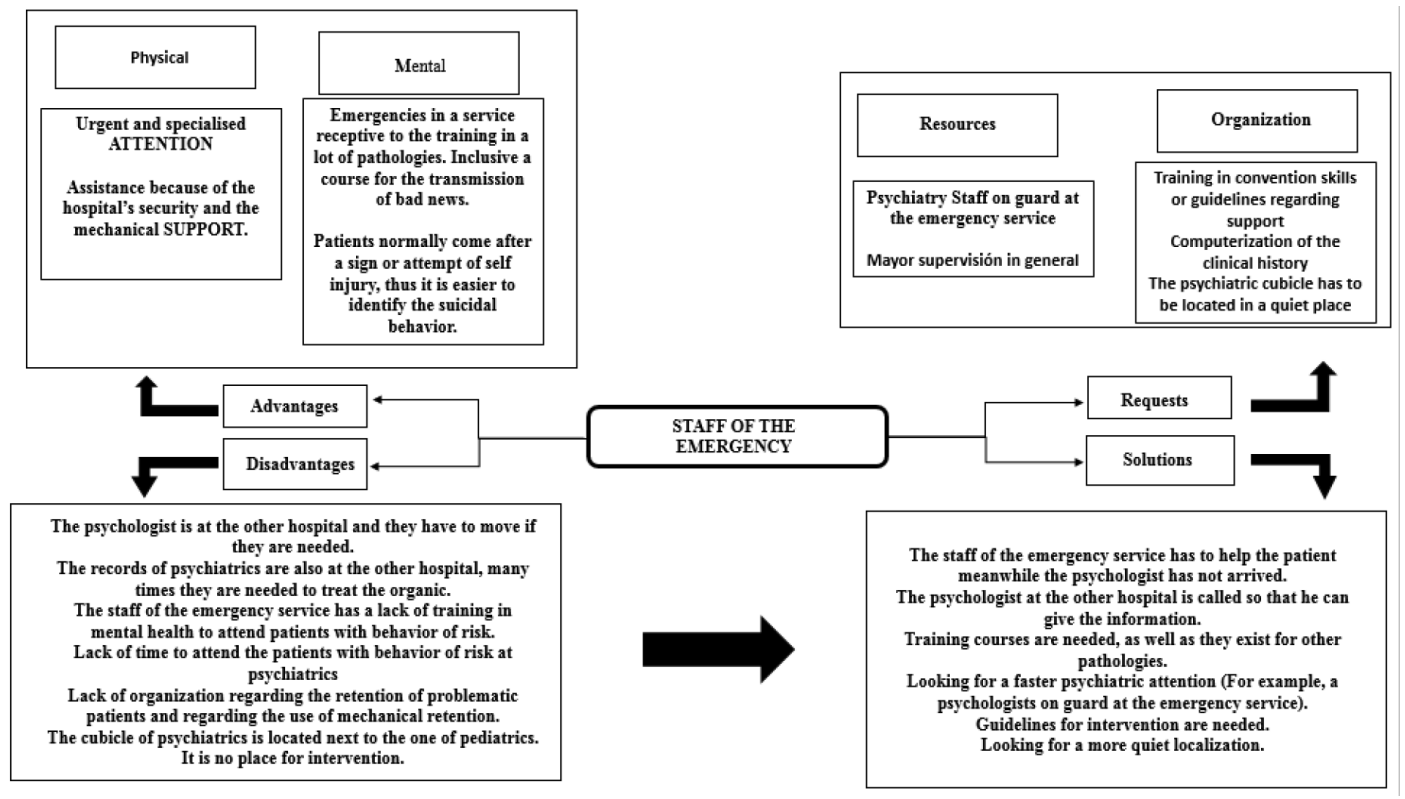

Figure 2 - Risk behavior intervention by personal emergency (owner elaboration)

The doctors of primary care are the health professionals who most frequently get in contact with the first clinical symptoms related to suicide, nevertheless, they are a collective who think from themselves they have a large gap in abilities of detection and treatment of patients with suicidal behaviors. They also refer to the need of training they require for the care of patients with this kind of behavior or those who are in a situation of suicide risk, and also for the care of psychiatric patients in general. Luoma and Martin point out that most of the people who die through suicide have had contact with the primary care services during the previous months, particularly the adult population, while there exists a percentage of cases that never come in contact with the Mental Health professionals ${ }^{(30)}$. This group of health professionals, besides maintaining a close relationship with the patient, is highly connected with the social environment of the later. This means that the professional has a large ability to have relevant information that allows the identification of a potential suicide risk. This fact highlights the importance of interventions related to suicide prevention in the field of primary care and the impact it would have in the reduction of suicide rates. For this reason, giving the doctors of primary care training in this area becomes a priority.

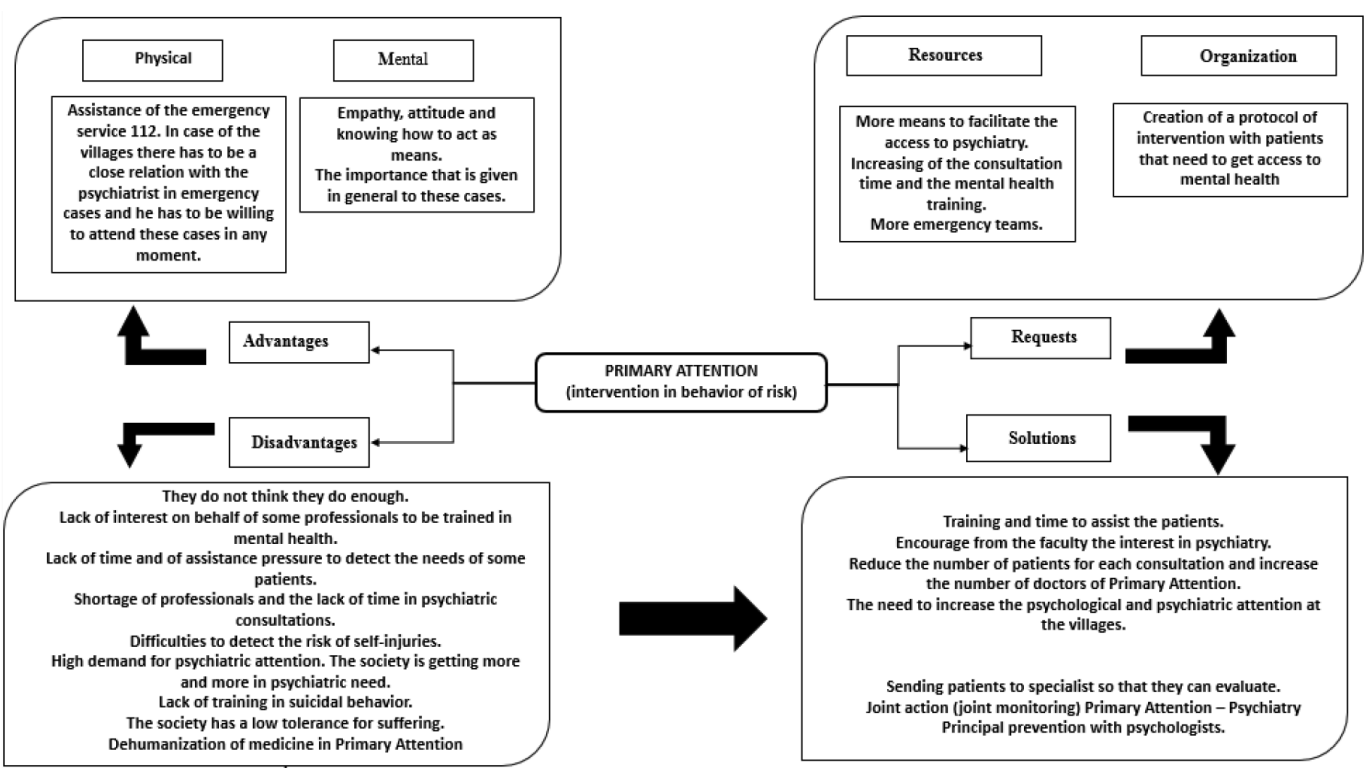

Figure 3 - Intervention in risk behaviors of staff according to attention of primary (owner elaboration) 
Psychiatrists consider that suicidal behavior signifies a high number of psychiatric emergencies and that they cause an elevated use of health resources, what brings them consequently to a priority in their clinical practice. In this sense, this group emphasizes on the need of considering the prevention of these behaviors as the prime course of action for the approach of this health problem. For these professionals, the mayor difficulty lies in identifying patients who present manipulative behavior and their care during crisis situations. Regarding this kind of behaviors of para-suicide, Laget emphasizes on the existence of a psychological profile that is more altered in in- dividuals with a background of repeated suicide attempts compared with other types of attempts ${ }^{(31)}$. In a recent study, Parra Uribe and Blasco-Fontecilla obtained as results that people who commit suicide had received less accomplished prior monitoring on behalf of the psychiatric and mental health services tan people who commit a failed suicide attempt; estimating that for $92 \%$ of the persons who commit suicide, it is their first or second attempt ${ }^{(32)}$. These data show comorbidity with personality disorders or the presumed existence of secondary benefits in some patients who repeatedly present para-suicidal behaviors.

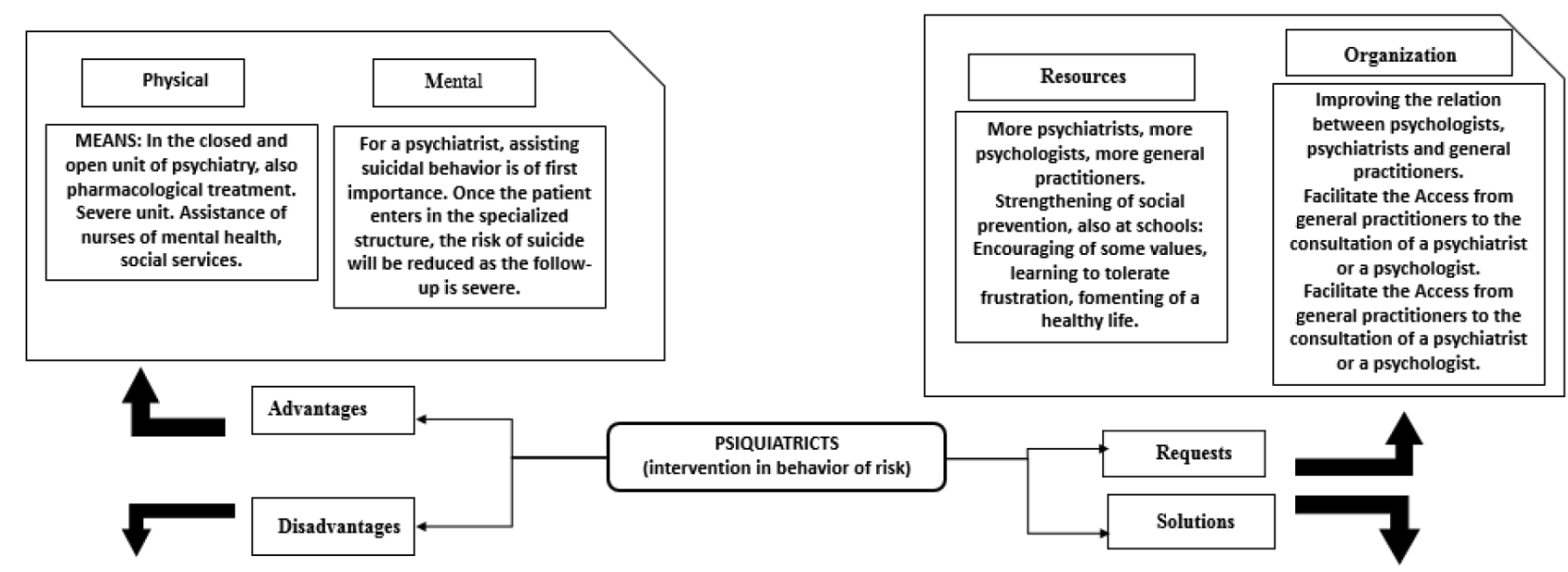

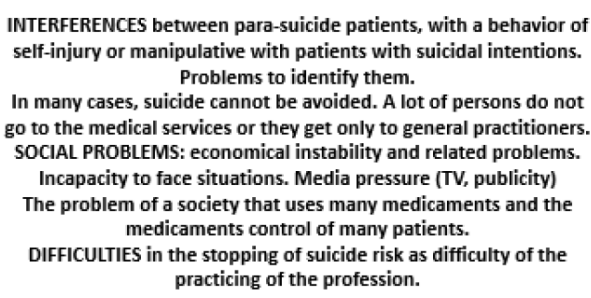

In case of doubt, use the most conservative method or make more prevention / social education. Education in assertiveness.

More prevention at social level. More control on publicity. Foment the psychological attention to try to avoid giving medicines to people without any need.

Time to work without pressure and with a good capacity of intervention. Meetings with the general practitioners to give and share information.

Figure 4 - Intervention in behaviour of risk according to psychiatrists. (Owner elaboration)

Psychologists focus on the socio-familiar environment of these people and they highlight the importance of support of the family in these cases. Thus, Sun presents the task that the nursing staff can carry out regarding the education of relatives of patients who are discharged from the hospital after a suicide attempt, in order to achieve appropriate support and care in the family environment ${ }^{(33)}$. These professionals are also aware of the importance of the prevention of suicidal behavior and they are a key element for the intervention in this field. In this sense, they make reference to the advantage of the existence of intervention teams in the community with respect to the following-up of patients with suicide risk. These teams have proved to be highly effective in suicide prevention $^{(34)}$. Finally, we have to highlight that this professional group points out, on a significant way, the lack of time for assisting these patients as an important limitation of the public health system.
Approach and treatment of suicidal behavior in the clinical practice of different groups of health professionals in Spain: results of the project EUREGENAS Muñoz JL, Gómez MCS, Vicario BP, Martín MAF 


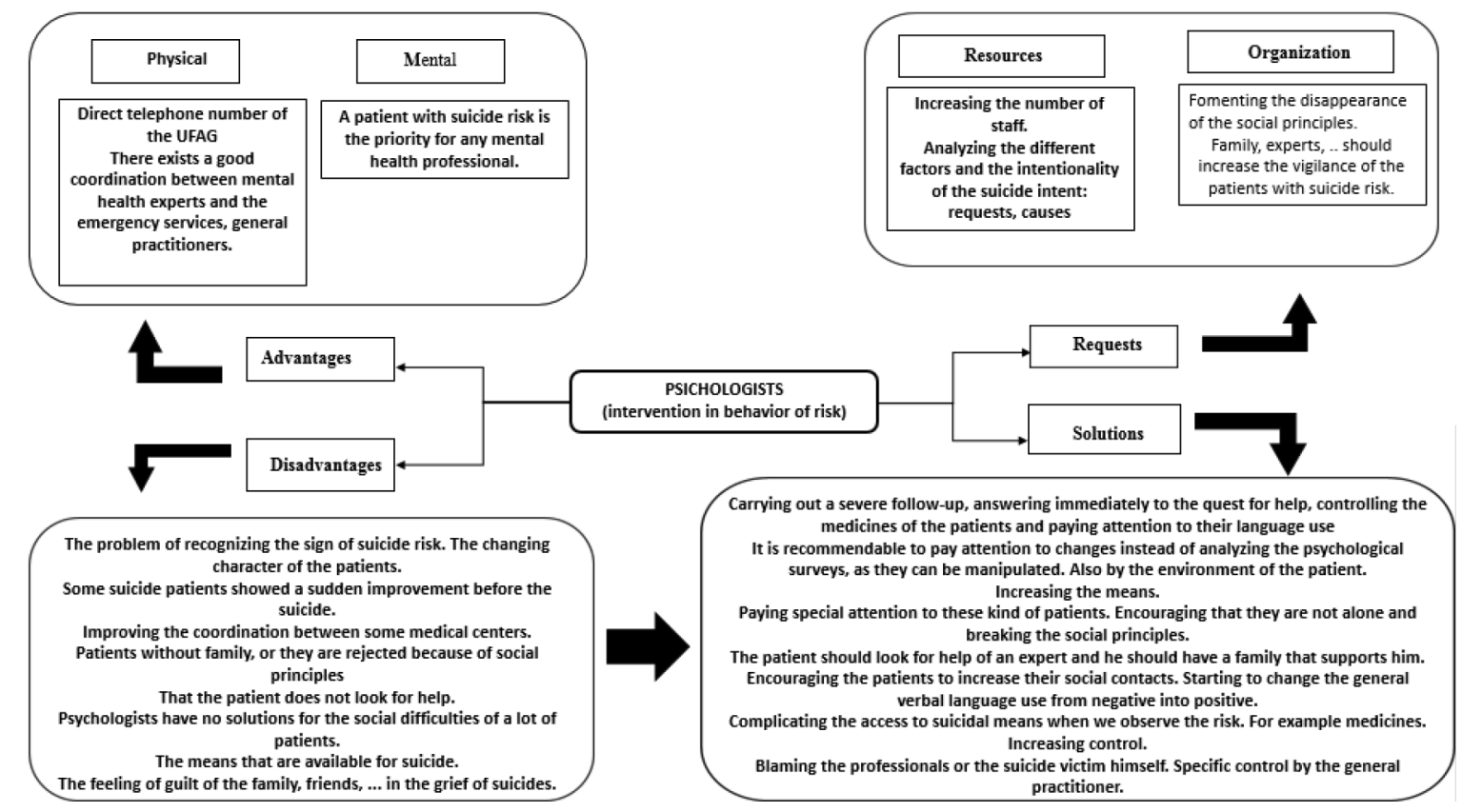

Figure 5 - Intervention in behaviour of risk according to psychologists. (Owner elaboration)

\section{CONCLUSIONS}

The results of this study are an important contribution in the detection, treatment and prevention of suicidal behavior. New research projects in this field are needed. The group of professionals that has participated in this research agrees on emphasizing on the great importance of suicide as a public health problem and on considering the resources as insufficient for its approach. The difficulties that exist

\section{REFERENCES}

1. España. Instituto Nacional de Estadística (INEbase). Defunciones según la Causa de Muerte. Madrid; 2012.

2. Dyregrov K. What do we know about needs for help after suicide in different parts of the world? A phenomenological perspective. Crisis, [Internet]. 2011 [cited 2014 sep. 19]; 32(6); 310-318. Available from: http://www.ncbi.nlm.nih.gov/ pubmed/21940240 DOI: 10.1027/0227-5910/a000098

3. WHO. Suicide prevention (SUPRE). World Health Organization. Geneva; 2005

4. Kovess-Masfety V, Boyd A, Haro J M, Bruffaerts, R, Villagut, G, Lépine,J P, Gasquest, J. , Alonso, J. High and low suicidality in Europe: a fine-grained comparison of France and Spain within the ESEMeD surveys. J Affect Disord, [Internet]. 2011 [cited 2014 sep. 19]; 133(1-2): 247-256. Available from: http://www.ncbi. nlm.nih.gov/pubmed/21621264 doi: 10.1016/j.jad.2011.04.014 to detect it and the care show the need to create prevention programs and intervention strategies in this area. In this sense, the project EUREGENAS represents an important breakthrough in the prevention of suicide in Europe and it provides opportunities for the development of future intervention projects in this field on European level.

5. Lester D, Yang B. Regional and time-series studies of suicide in nations of the world. Arch Suicide Res, [Internet]. 2005 [cited 2014 sep. 19]; 9(2): 123-133. Available from: http://www.tandfonline.com/doi/abs/10.1080/13811110590903972\#.VBsU1vl_vng DOI: 10.1080/13811110590903972

6. Chen Z, Zhang Y, Liu Z, Liu Y, Dyregrov A. Structure of the Children's Revised Impact of Event Scale (CRIES) with children and adolescents exposed to debris flood. PLoS One, [Internet]. 2012 [cited 2014 sep. 19]; 7(8). Available from: http://www.plosone.org/article/ info\%3Adoi\%2F10.1371\%2Fjournal.pone.0041741 e41741. DOI: 10.1371/journal.pone.0041741

7. Neeleman J. Beyond risk theory: suicidal behavior in its social and epidemiological context. Crisis. 2002; 23(3): 114-120. 
8. Gene, AR. Environment Interaction and Suicidal Behavior. In: Dwivedi Y, editor. The Neurobiological Basis of Suicide. Frontiers in Neuroscience, capítulo 10. Filadelfia: Boca Raton; 2010. Available from: http://www.ncbi.nlm.nih.gov/books/NBK107200/

9. Hawton, K, Harriss, L, Hodder, K, Simkin, S, Gunnell, D. The influence of the economic and social environment on deliberate self-harm and suicide: an ecological and person-based study. Psychol Med. 2001; 31(5):827-836.

10. Leenaars A, Cantor C, Connolly J, EchoHawk, M, Gailiene, D, He, ZX, Kokorina, N, Lester, D, Lopatin, AA, Rodriguez, M, Schlebusch, L, Takahashi, Y, Wenckstern, S. Controlling the environment to prevent suicide: international perspectives. Can J Psychiatry. 2000; 45(7):639-644.

11. Schneider, B, Grebner, K., Schnabel, A, Hampel, H, Georgi, R, Seidler, A. Impact of employment status and work-related factors on risk of completed suicide. A case-control psychological autopsy study. Psychiatry Res, [Internet]. 2011 [cited 2014 sep. 19]; 190(2-3), 265-270. Available from: http:// www.ncbi.nlm.nih.gov/pubmed/21890214 doi: 10.1016/j. psychres.2011.07.037

12. Corcoran P, Nagar A. Suicide and marital status in Northern Ireland. Soc Psychiatry Psychiatr Epidemiol, [Internet]. 2010, [cited 2014 sep. 19]; 45(8): 795-800. Available from: http:// link.springer.com/article/10.1007/s00127-009-0120-7\# DOI: 10.1007/s00127-009-0120-7

13. Yamauchi T, Fujita T, Tachimori $H$, Yamauchi, T,Fujita, $T$, Tachimori, H, Takeshima, T, Inagaki, M, Sudo, A. Age-adjusted relative suicide risk by marital and employment status over the past 25 years in Japan. J Public Health (Oxf) [Internet]. 2013 [cited 2014 sep. 19]; 35(1): 49-56. Available from: http://jpubhealth.oxfordjournals.org/content/35/1/49.short doi: 10.1093/pubmed/fds054

14. Gearing R E, Lizardi D. Religion and suicide. J Relig Health, [Internet]. 2009, [cited 2014 sep. 19]; 48(3): 332-341. Available from http://link.springer.com/article/10.1007/s10943008-9181-2\#page-1 DOI: 10.1007/s10943-008-9181-2

15. Hilton S C, Fellingham G W, Lyon, J L. Suicide rates and religious commitment in young adult males in Utah. Am J Epidemiol. 2002; 155(5): 413-419.

16. Neeleman J, de Graaf R, Vollebergh W. The suicidal process; prospective comparison between early and later stages. J Affect Disord, [Internet]. 2004 [cited 2014 sep. 19]; 82(1): 43-52. Available from http://www.sciencedirect.com/ science/article/pii/S0165032703002325 DOI: $10.1016 / \mathrm{j}$. jad.2003.09.005

17. Runeson B S, Beskow J, Waern M. The suicidal process in suicides among young people. Acta Psychiatr Scand. 1996; 93(1): 35-42.
18. Gibb S J, Beautrais A L, Fergusson D M. Mortality and further suicidal behaviour after an index suicide attempt: a 10-year study. Aust N Z J Psychiatry, [Internet]. 2005, [cited 2014 sep. 19]; 39(1-2): 95-100. Available from http://neurotech.org.nz/research/publications/papers/0334.pdf DOI: 10.1111/j.1440-1614.2005.01514.x

19. Foster T, Gillespie K, McClelland R. Mental disorders and suicide in Northern Ireland. Br J Psychiatry. 1997; 170: 447-452.

20. Oldham J M. Borderline personality disorder and suicidality. Am J Psychiatry, [Internet]. 2006 [cited 2014 sep. 19]; 163(1): 20-26. Available from http://journals.psychiatryonline.org/article. aspx?articleid=177987 DOI: 10.1176/appi. ajp.163.1.20

21. Osborn D, Levy G, Nazareth I, King M. Suicide and severe mental illnesses. Cohort study within the UK general practice research database. Schizophr Res, [Internet]. 2008 [cited 2014 sep. 19]; 99(1-3): 134-138. Available from: http://www. sciencedirect.com/science/article/pii/S0920996407005361 en DOI: 10.1016/j.schres.2007.11.025

22. Hawton K, Houston K, Haw C, Townsend, E, Harris, L. Comorbidity of axis I and axis II disorders in patients who attempted suicide. Am J Psychiatry. 2003; 160(8): 1494-1500.

23. Kessler R C, Borges G, Walters E E. Prevalence of and risk factors for lifetime suicide attempts in the National Comorbidity Survey. Arch Gen Psychiatry. 1999; 56(7): 617-626.

24. Nock, M K, Kessler R C. Prevalence of and risk factors for suicide attempts versus suicide gestures: analysis of the National Comorbidity Survey. J Abnorm Psychol, [Internet]. 2006 [cited 2014 sep. 19]; 115(3): 616-623. Available from http://jreiss.psych.udel.edu/616.pdf DOI: 10.1037/0021843X.115.3.616

25. Sánchez, M.C.; Delgado; M.C, Santos, M. C. El proceso de la Investigación cualitativa. Manual de procedimiento: ejemplificación con una tesis doctoral. Valladolid: Edintras; 2013

26. Miles M B, Huberman A. Qualitative data analysis: an expanded sourcebook. California: Sage; 1994

27. Pagura J, Fotti S, Katz L Y, Sareen, J, Swampy Cree Suicide Prevention Team. Help seeking and perceived need for mental health care among individuals in Canada with suicidal behaviors. Psychiatr Serv, [Internet]. 2009 [cited 2014 sep. 19]; 60(7): 943-949. Available from: http://journals.psychiatryonline.org/article.aspx?articleid=100601 DOI: 10.1176/ appi.ps.60.7.943

28. Jauregui J, Martinez M L, Rubio G, Santo Domingo, J. Patients who attempted suicide and failed to attend mental health centres. Eur Psychiatry. 1999; 14(4):205-209.
Approach and treatment of suicidal behavior in the clinical practice of different groups of health professionals in Spain: results of the project EUREGENAS Muñoz JL, Gómez MCS, Vicario BP, Martín MAF 
29. Milner A, Kolves K, Kolves, K, Gladman, B, De Leo, D. Treatment priority for suicide ideation and behaviours at an Australian emergency department. World J Psychiatry, [Internet]. 2013 [Cited 2014 sep. 19]; 3(2): 34-40. Available from: http://www.ncbi.nlm.nih.gov/pmc/articles/PMC3782185/ DOI: 10.5498/wjp.v3.i2.34

30. Luoma J B, Martin C E, Pearson J L. Contact with mental health and primary care providers before suicide: a review of the evidence. Am J Psychiatry. 2002; 159(6): 909-916.

31. Laget J, Plancherel B, Stephan P, Bolognini, M, Corcos, M, Jeammet, $\mathrm{P}$, Halfon, $\mathrm{O}$. Personality and repeated suicide attempts in dependent adolescents and young adults. Crisis. 2006; 27(4):164-171

32. Parra Uribe I, Blasco-Fontecilla H, Garcia-Pares G, Giró, M, Llorens, M, Cebriá, A, De León-Martínez, V, Pérez-Solà, V, Palao, DJ. Attempted and completed suicide: not what we expected? J Affect Disord, [Internet]. 2013 [Cited 2014 sep. 19]; 150(3): 840-846. Available from: http://www.ncbi.nlm. nih.gov/pubmed/23623420 DOI: 10.1016/j.jad.2013.03.013
33. Sun F K, Long A, Huang X Y Huang HM. Family care of Taiwanese patients who had attempted suicide: a grounded theory study. J Adv Nurs, [Internet]. 2008 [Cited 2014 sep. 19]; 62(1):53-61. Available from: http://onlinelibrary.wiley.com/ doi/10.1111/j.1365-2648.2007.04578.x/abstract;jsessionid $=31 \mathrm{C} 22 \mathrm{~F} 8893 \mathrm{D} 5 F 00 D C 2 E 8 F 946 D D 23 C 210 . f 01 \mathrm{t} 03$ ?denied $\mathrm{A}$ ccessCustomisedMessage $=$ \&userlsAuthenticated=false doi: 10.1111/j.1365-2648.2007.04578.x

34. Tyrer P. The future of specialist community teams in the care of those with severe mental illness. Epidemiol Psichiatr Soc. 2007;16 (3): 225-230. 